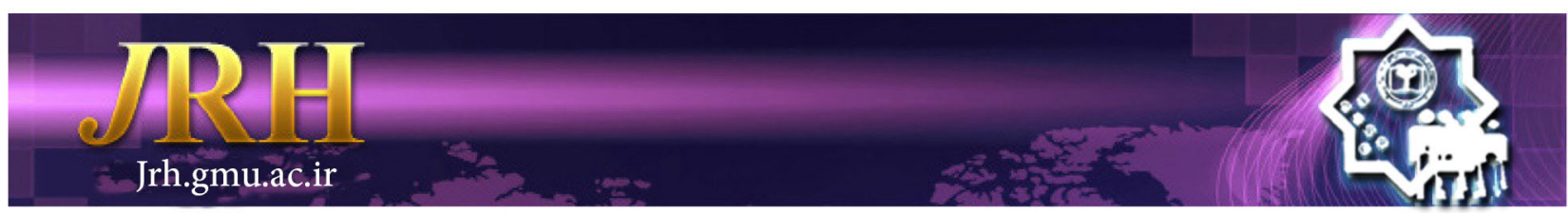

\title{
The relations among well-being outcomes and motives, religiosity, and personality factors in Malaysian muslim university students \\ Naser Aghababaei ${ }^{1}$, Mustafa Tekke ${ }^{2}$
}

\author{
Journal of Research \& Health \\ Social Development \& Health Promotion \\ Research Center \\ Vol. 8, No.6, Nov \& Dec 2018 \\ Pages: 565- 571 \\ DOI: $10.29252 / j r h .8 .6 .565$ \\ Brief Article
}

1. Correspondence to: Department of Behavioral Sciences, the Institute for Research and Development in the Humanities (SAMT), Jalale-Ale-Ahmad, Yadegare Emam Bridge, Tehran, Iran

Email: naseragha@gmail.com

2. Department of Psychology and Counseling, Faculty of Education, International Islamic University Malaysia, Kuala Lumpur, Malaysia

Received: 12 Agu 2014

Accepted: 21 Sep 2014

How to cite this article: Aghababaei N, Tekke $\mathrm{M}$. The relations among well-being outcomes and motives, religiosity, and personality factors in Malaysian Muslim university students. J Research \& Health2018; 8(6): 565- 571.

\begin{abstract}
A major focus of attention in psychology has been on the consequences and determinants of well-being. Religiosity and personality have both been shown to predict well-being and mental health, but the two predictors have not often been investigated together. The relations among well-being outcomes and motives, religiosity, and personality factors were investigated in a Malay muslim context. 255 volunteer university students completed satisfaction with life scale, subjective happiness scale, rosenberg's self-esteem scale, hedonic and eudaimonic motives for activities, religious orientation scalerevised, gratitude toward God questionnaire, and the 60-item honesty-humility, emotionality, extraversion, agreeableness, conscientiousness, openness personality inventory-revised. The data were analyzed using the statistics such as partial correlation, and hierarchical regression. Results showed that religiosity measures were associated with higher levels of honesty-humility, conscientiousness, agreeableness, happiness, life satisfaction, self-esteem, and a eudaimonic way of living. Religiosity had null or weak relationships with well-being outcomes and motives, beyond broad personality factors. Religiosity and honestyhumility may be relatively more important for eudaimonia than for hedonia.
\end{abstract}

Keywords: Happiness, Personality, Religion, Well-being

\section{Introduction}

Subjective Well-Being (SWB), a person's cognitive and emotional evaluations of his life, includes what lay people call happiness [1]. People from around the world strongly desire SWB or happiness, and happy persons are successful across multiple life domains, including marriage, friendship, income, job and academic performance, and health not only because success makes people happier, but also because happiness engenders success [2-4]. Personality has long been recognized as a strong predictor of happiness. There is also some evidence of a genetic link between SWB and personality [5]. Extraversion influences people's positive affects, whereas Neuroticism determines people's negative affects [6]. Furthermore, a growing body of research has found positive links between happiness and various aspects of religiousness.

Religiosity and personality have both been shown to predict happiness, but the two predictors have not often been investigated together. Francis and Lester [7] found that, among college students in the United States, the positive link between religiosity and happiness is independent 
of the personality factors of Eysenck. Using single-item measures of life satisfaction and religiosity, Aghababaei [8] found that the positive links between religiosity and SWB are independent of individual differences in the HEXACO (Honesty-Humility, Emotionality, eXtraversion, Agreeableness, Conscientiousness, Openness) personality factors. Robbins, Francis and Edwards [9] found a positive correlation between prayer frequency and happiness, but only before controlling for individual differences in eysenck's personality factors. Additionally, it has been found that trait gratitude explained additional variance in life satisfaction and mental health when added to religious gratitude, but the reverse was not the case [10]. Others have even found negative links between religion and SWB [11]. Given these conflicting results, further research is necessary to explore the relations among religion, happiness and personality.

In this paper, we explore whether religiousness relates to well-being outcomes and motives among a sample of Malaysian muslims, a cultural context where psychological studies have not been frequently conducted. Higher levels of well-being are expected to associate with higher religiosity, and Extraversion (defined in the HEXACO framework by facets social self-esteem, social boldness, sociability, and liveliness). As with previous studies conducted both in Iran and in the United States [8,12], religiosity measures are expected to positively correlate with HonestyHumility (defined in the HEXACO framework by facets sincerity, fairness, greed-avoidance, and modesty), Agreeableness (defined by facets forgiveness, gentleness, flexibility, and patience), and Conscientiousness (defined by facets organization, diligence, perfectionism, and prudence). We also are interested in knowing whether the links between religiosity and well-being remain beyond personality factors. Since a host of studies have shown that intrinsic religiosity (defined as a mature form of religiosity serving as a master motive for one's way of life), more than extrinsic religiosity (defined as the immature faith serving as a means of convenience for self-serving social or psychological ends), associates with and psychological adjustment, including happiness and also with personality factors such as Agreeableness and Conscientiousness [4,13-15], we expect to find the same pattern of results among our sample. Additionally, with few notable exceptions that have shown differential and overlapping effects of hedonic and eudaimonic approaches to well-being [16], there has been very little work comparing hedonia and eudiamnia. We would like to see how these two approaches converge and diverge in their associations with religiosity and personality factors.

\section{Method}

This study used a cross-sectional design, and a convenience non-random sampling method. Data were collected using self-administered questionnaires during the 2014 academic year. Participants from the international Islamic university Malaysia, recruited orally and through advertisements on campus, responded to questionnaire booklets in group settings of various sizes. All participation was voluntary, and in conformity with institutional ethical guidelines.

Participants were 194 female and 61 male Malaysian muslim university students, with ages ranging from 18 to 56 (mean age $=24.38)$. Participants completed the questionnaire booklets which consisted of the English versions of the following measures. A five point Likert-type scale was applied for all items described in this section, unless indicated otherwise

The widely used 5-item Satisfaction with Life scale was used to measure the cognitive aspect of SWB. A two-month test-retest correlation of this scale was 0.82 , and its coefficient alpha was 0.87 [17]. The 4-item Subjective Happiness Scale (SHS) was used as a measure of global happiness. Sample item is "In general I consider myself: 1= not a very happy person to $7=$ a very happy person". Coefficient alphas of the SHS ranged from 0.79 to 0.94 , and a one-month 
test-rest reliability was 0.85 [18]. Rosenberg's 10-item Self-Esteem Scale was used to measure self-esteem, a construct distinguishable from, yet closely related to SWB [19]. The 9-item Hedonic and Eudaimonic Motives for Activities was applied to assess eudaimonia and hedonia as motives for activities [16]. This newly designed scale asks participants to what degree they typically approach their activities with hedonic (e.g. "Seeking relaxation") or eudaimonic (e.g. "Seeking to pursue excellence or a personal ideal") intentions. Coefficient alphas of the eudaimonia and hedonia scales were 0.82 and 0.85 , respectively [16]. The 14-item Religious Orientation Scale-Revised was used to measure intrinsic, extrinsic personal, and extrinsic social religiosity [20]. Coefficient alphas of these religiosity scales ranged from 0.75 to 0.85 [21]. A 4-item Gratitude toward God Questionnaire was used to measure religious gratitude [22]. Coefficient alphas of the gratitude questionnaire were from 0.89 to 0.92 [21]. Personality factors were measured using the 60-item HEXACO Personality InventoryRevised, assessing Honesty-Humility, Emotionality, eXtraversion, Agreeableness, Conscientiousness, and Openness. The internal consistency reliabilities of the HEXACO factors in a college sample ranged from 0.77 to .80 [23].

The data were analyzed using descriptive and inferential statistics including partial correlation, and hierarchical regression analyses. The data were analyzed using the software SPSS-18.

\section{Results}

More demographic information has been depicted in Table 1.

Table 1 The demographic information of the study sample

\begin{tabular}{lcc}
\hline Gender & $194(76.1 \%)$ female & $61(23.9 \%)$ male \\
Age & Mean: 24.38 & SD: 5.30 aa \\
Marital status & $220(86.3 \%)$ single & $35(13.7)$ married \\
Religion & $255(100 \%)$ Muslim & \\
Degree & $61(23.9 \%)$ graduate & $194(76.1 \%)$ undergraduate \\
Ethnicity & $254(99.6 \%)$ Malay & $1(0.4 \%)$ unspecified \\
\hline
\end{tabular}

Table 2 provides intercorrelations among the study variables. As expected, religiosity was associated with higher levels of SWB, selfesteem, Honesty-Humility, Agreeableness, and Conscientiousness.

A series of hierarchical regressions was used to see the unique contribution of religiosity in well-being constructs by controlling for broad personality factors. In doing so, religiosity was entered in step 2, after entering personality factors in step 1. With the effects of HEXACO dimensions controlled, intrinsic religiosity failed to predict SWB, self-esteem and hedonic motive, but predicted $2 \%$ of variance in eudaimonic motive $(p<0.05)$. The same method was used for the three other religiosity measures (the two extrinsic religiosity, and gratitude to God). Extrinsic personal religiosity too failed to significantly predict SWB and self-esteem, but predicted $2 \%$ of variance in eudaimonic motive $(\mathrm{p}=0.01)$ and $1 \%$ of variance in hedonic motive $(\mathrm{p}=0.068)$, beyond HEXACO dimensions. Extrinsic social religiosity, after controlling for HEXACO factors, predicted $7 \%$ of variance in life satisfaction $(\mathrm{p}<0.01)$, $1 \%$ variance in happiness $(p<0.05)$, but failed to predict self-esteem and well-being motives. Religious gratitude, after controlling for HEXACO dimensions, predicted 3\% variance in happiness $(p<0.01)$, but failed to predict other well-being variables.

We investigated the effects of hedonia and eudaimonia on the other's relation to variables under study, by conducting partial correlation analyses (Table 3). Results showed that religiosity had positive relations with eudaimonia, and null or negative relations with hedonia. Honesty-Humility factor also had a positive relation with eudaimonia but a negative one with hedonia. 


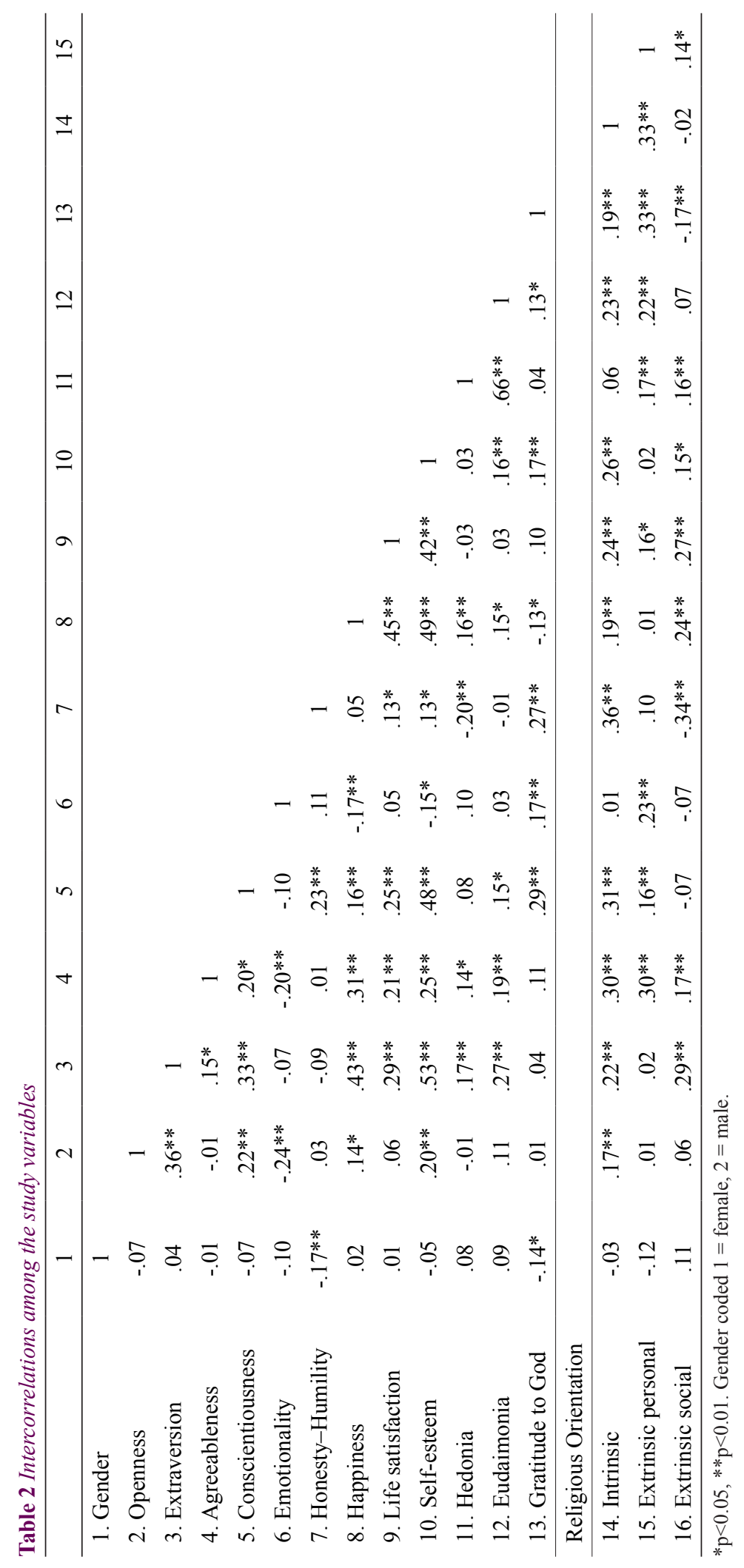


Table 3 Partial correlations between hedonia, eudaimonia, and other variables

\begin{tabular}{lcc}
\hline & $\begin{array}{c}\text { Hedonia } \\
\text { (control for eudaimonia) }\end{array}$ & $\begin{array}{c}\text { Eudaimonia } \\
\text { (control for hedonia) }\end{array}$ \\
\hline Openness & -.10 & $.14^{*}$ \\
Extraversion & -.02 & $.24^{* *}$ \\
Agreeableness & .02 & $.14^{*}$ \\
Conscientiousness & -.01 & $.13^{*}$ \\
Emotionality & .11 & -.05 \\
Honesty-Humility & $-.23^{* *}$ & $.13^{*}$ \\
Happiness & .06 & .08 \\
Life satisfaction & -.04 & .04 \\
Self-esteem & -.06 & $.17^{* *}$ \\
Gratitude to God & -.03 & .12 \\
Religious orientation & & $.21^{* *}$ \\
Intrinsic & -.06 & $.13^{*}$ \\
Extrinsic personal & .05 & -.04 \\
Extrinsic social & $.15^{*}$ & \\
\hline * $<0.05 ; * * p<0.01$ & &
\end{tabular}

\section{Discussion}

Eudaimonia and hedonia are two ways of living. Eudaimonia is focused on what is intrinsically worthwhile to human beings and involves seeking to use and develop the best in oneself, whereas hedonia involves seeking personal pleasure, enjoyment, and comfort. Hedonic and eudaimonic approaches to well-being are conceptuallydistinct, whereasempiricalfindings have shown differential and overlapping effects of these two approaches on people's life [16]. To distinguish these overlapping variables, one cannot rely on raw correlations as the sole method of analysis; at minimum, multiple regression or partial correlations should be reported to see their unique and divergent correlations with variables such as happiness, religious orientation, and personality factors. A prior study conducted in Iran suggested that despite being good for eudaimonia, HonestyHumility may not be helpful for hedonia [24]. In the present study, Honesty-Humility had null or positive weak relations with well-being outcomes, a positive link with eudaimonia, but a negative relation with hedonia, which confirms previous findings and speculations $[4,24]$. These findings may suggest that not being self-entitled, materialistic, manipulative and exploitive of others, which is the hallmark of the Honesty-Humility factor, may have some adaptive advantages for oneself and/or for others, and may even be necessary for living a virtuous life, but it does not seem to have much contribution to hedonia and variables such as SWB which are based on a hedonic conceptualization of well-being.

Religiosity, as expected, was positively associated with well-being outcomes and eudaimonic motives. Such findings is in line with past research and may support the notion that religiosity-happiness link is mediated by eudaimonia. In fact, eudaimonic variables like purpose in life have been proposed to mediate this relationship [25]. Religion provides meaning and enhances the sense of purpose in life, through which it may contribute to people's wellness $[15,25,26]$. After controlling for personality factors, however, many of the links between religiosity and well-being variables disappeared. We conclude then that religiosity-happiness link is minimal and limited in extent, since it applies to some aspect of religion and positive functioning but not to others, and because this link is, to some extent, due to personality. Further research is necessary to test and confirm this conclusion, however.

Another finding of the present study was that higher scorers on Honesty-Humility reported 
higher scores on religiosity, particularly on more adjusted and mature forms of religiosity. High scorers on Honesty-Humility tend to be genuine in interpersonal relations, avoid fraud and corruption, and not to be especially motivated by monetary or socialstatus considerations. These traits appear as highly prized human dispositions in many religions, and religious people are expected to report higher scores on this factor because they are prosocial, empathic and because it is important for religious people to be honest and fair [27]. According to Allport's model of religious orientation, the intrinsic dimension should predict whether religious persons will act congruently or incongruently with their religious principles [13]. In the current study, the positive correlation between intrinsic religiosity and Honesty-Humility not only supports Allport's theory, but also provides additional construct validity of the HonestyHumility factor.

\section{Conclusion}

Religiosity in this study had null or weak relationships with well-being, beyond personalityfactors. Religiosity and HonestyHumility may be relatively more important for eudaimonia hedonia. Our sample participants were recruited through non-random purposive sampling. While this means that the study is not generalizable to the wider Malaysian population, the goalhere was not to estimate overall means for the key variables. The sample is sufficient for theparticular goals of testing the relationship of religious orientations and well-being variables (while controlling for personality factors). Moreover, while student samples are often consideredconvenient, here it may represent an advantage for promoting comparable future research in othercultures. That is, this study is easier for other researchers to replicate. Nevertheless, the use of aconvenience sample of university students and the use of self-reports were limitations of thisresearch. Future research should use multiple methods of measurement, examine greater diversityamong individuals, and study unexamined religious groups with a balanced sex ratio. Suchresearch would show whether religion contribute to living a good life

\section{Acknowledgments}

The authors would like to thank the participants.

\section{Contribution}

Study design: NA, MT

Data collection and analysis: NA, MT

Manuscript preparation: NA

\section{Conflict of Interest}

The authors declare that they have no competing interests.

\section{Funding}

The authors received no financial support for the research, authorship and/ or publication of this article.

\section{References}

1- Diener E, Oishi S, Lucas RE. Personality, culture, and subjective well-being: Emotional and cognitive evaluations of life. Annu Rev Psychol2003; 54(1): 403-25.

2- Lyubomirsky S, King L, Diener E. The benefits of frequent positive affect: Does happiness lead to success? Psychol Bull2005; 131(6): 803-55.

3- Argyle M. Is happiness a cause of health? Psychol Health1997; 12(6): 769-81.

4- Aghababaei N, Mohammadtabar S, Saffarinia M. Dirty Dozen vs. the $\mathrm{H}$ factor: comparison of the Dark Triad and Honesty-Humility in prosociality, religiosity, and happiness. Pers Indiv Differ2014; 67: 6-10.

5- Weiss A, Bates TC, Luciano M. Happiness is a personal (ity) thing: The genetics of personality and well-being in a representative sample. Psychol Sci2008; 19(3): 205-10.

6- Steel P, Schmidt J, Shultz J. Refining the relationship between personality and subjective well-being. Psychol Bull2008; 134(1): 138-61.

7- Francis LJ, Lester D. Religion, personality and happiness. Journal of Contemporary Religion1997; 12(1): 81-6.

8- Aghababaei N. God, the good life, and HEXACO: The relations among religion, subjective well-being and personality. Ment Health Relig Cult2014; 17(3): 284-90. 9- Robbins M, Francis LJ, Edwards B. Prayer, personality and happiness: A study among undergraduate students 
in Wales. Ment Health Relig Cult2008; 11(1): 93-9.

10- Aghababaei N, Tabik MT. Gratitude and mental health: Differences between religious and general gratitude in a Muslim context. Ment Health Relig Cult2013; 16(8): 761-6. 11- Brown PH, Tierney B. Religion and subjective wellbeing among the elderly in China. J Socio Econ2009; 38(2): 310-9.

12- Aghababaei N, Wasserman JA, Nannini D. The religious person revisited: cross-cultural evidence from the HEXACO model of personality structure. Ment Health Relig Cult2014; 17(1): 24-9.

13- Allport GW, Ross JM. Personal religious orientation and prejudice. J Pers Soc Psychol1967; 5(4): 432-43.

14- Flere S, Lavrič M. Is intrinsic religious orientation a culturally specific American Protestant concept? The fusion of intrinsic and extrinsic religious orientation among non-Protestants. Eur J Soc Psychol2008; 38(3): 521-30.

15- Francis LJ, Jewell A, Robbins M. The relationship between religious orientation, personality, and purpose in life among an older Methodist sample. Ment Health Relig Cult2010; 13(7-8): 777-91.

16- Huta V, Ryan RM. Pursuing pleasure or virtue: The differential and overlapping well-being benefits of hedonic and eudaimonic motives. J Happiness Stud2010; 11(6): 735-62.

17- Diener E, Emmons RA, Larsen RJ, Griffin S. The satisfaction with life scale. J Pers Assess 1985; 49(1): 71-5. 18- Lyubomirsky S, Lepper HS. A measure of subjective happiness: Preliminary reliability and construct validation.
Soc Indic Res1999; 46(2): 137-55.

19- Rosenberg M. Society and the adolescent selfimage. Philadelphia: Princeton university press; 1965.

20- Gorsuch RL, McPherson SE. Intrinsic/extrinsic measurement: I/E-revised and single-item scales. J Sci Study Relig1989; 28(3): 348-54.

21- Aghababaei N. Between you and God, where is the general factor of personality? Exploring personalityreligion relationships in a Muslim context. Pers Individ Dif2013; 55(2): 196-8.

22- Krause N. Gratitude toward God, stress, and health in late life. Res Aging2006; 28(2): 163-83.

23- Ashton MC, Lee K. The HEXACO-60: A short measure of the major dimensions of personality. J Pers Assess 2009; 91(4): 340-5.

24- Aghababaei N, Arji A. Well-being and the HEXACO model of personality. Pers Individ Dif2014; 56: 139-42. 25- Sillick WJ, Cathcart S. The relationship between religious orientation and happiness: the mediating role of purpose in life. Ment Health Relig Cult2014; 17(5): 494-507.

26- Aghababaei N, Błachnio A. Purpose in life mediates the relationship between religiosity and happiness: Evidence from Poland. Ment Health Relig Cult2014; 17(8): 827-31.

27- Aghababaei N. Religious, honest and humble: Looking for the religious person within the HEXACO model of personality structure. Pers Individ Dif2012; 53(7): 880-3.

Copyright $\odot 2016$ ASP Ins. This open-access article is published under the terms of the Creative Commons Attribution-NonCommercial 4.0 International License which permits Share (copy and redistribute the material in any medium or format) and Adapt (remix, transform, and build upon the material) under the Attribution-NonCommercial terms. 